\title{
Inheritance of Resistance to Early Blight Disease in Tetraploid $\times$ Diploid Crosses of Potatoes
}

\author{
A.B. Herriott ${ }^{1}$ and F.L. Haynes, Jr. ${ }^{2}$ \\ Department of Horticultural Science, North Carolina State University, \\ Raleigh, NC 27695

\section{P.B. Shoemaker \\ Department of Plant Pathology, North Carolina State University Raleigh, NC 27695}

Additional index words. Solanum tuberosum, Solanum tuberosum Group phureja Solarium tuberosum Group stenotomum, potato breeding, heritability, first-division restitution gametes, $2 \mathrm{n}$ pollen, Alternaria solani

\begin{abstract}
Heritability of resistance to early blight disease in potatoes (Solarium tuberosum L.) incited by Alternaria solani (En. \& Martin) Ser. was estimated in tetraploid $\times$ diploid crosses. Susceptible tetraploid cultivars and breeding lines were the female parents. Diploids that produced a high proportion of first-division restitution (FDR) gametes and possessed different levels of early blight resistance were the male parents. Tubers from seedlings that resulted from the tetraploid $\times$ diploid crosses were planted in a field and artificially inoculated with spores of Alternaria solani. Resistance was measured as the slope $(r)$ of the regression of the logit of the percent defoliation of each plant vs. time. Higher $r$ values indicated lower resistance. Mean $r$ values ranged from 0.123 to 0.157 for the tetraploid parents, and from 0.054 to 0.116 for the diploid parents. Mean $r$ values for the tetraploid $\times$ diploid crosses were intermediate, ranging from 0.077 to 0.143 . Narrow-sense heritability $\left(h^{2}\right)$ was 0.815 . The partial correlation coefficient between $r$ and mean maturity values was -0.2086 .
\end{abstract}

Early blight, a leaf-spotting and defoliating disease incited by Alternaria solani (En. \& Martin) Ser., affects a wide range of solanaceous plants, including potatoes, where the primary effect of the disease is on the foliage. Germinating spores initiate lesions that expand to a diameter of 9 to $10 \mathrm{~mm}$. Lesions, which are easily identified by their target-like appearance, often coalesce and may cover a major portion of the leaf surface. Infected leaves soon senesce and abscise from the plant. Complete defoliation of a susceptible plant may occur within 6 weeks after initial infection. Because tubers generally form in the latter portion of the potato growing season, extensive defoliation of the plant may reduce tuber-. yields substantially. Harrison and Venette (1970) found 18\% to 39\% higher yields in fields treated with fungicide for

Received for publication 30 June 1988. Paper no. 11668 of the Journal Series of the North Carolina Agricultural Research Service, Raleigh, NC 276957643. The cost of publishing this paper was defrayed in part by the payment of page charges. Under postal regulations, this paper therefore must be hereby marked advertisement solely to indicate this fact.

'Former graduate student. Present address: Cornell Cooperative Extension of Rockland County, P.O. Box 1000, Thiells, NY 10984.

${ }^{2}$ Professor Emeritus, North Carolina State Univ. Present address: 5109 E. Durham Rd., Columbia, MD 21044.

${ }^{3}$ Professor. Present address: Mountain Horticultural Crops Research Station, 2016 Fanning Bridge Rd., Fletcher, NC 28732. control of early blight than in untreated fields. Although effective, fungicides must be applied frequently when the disease is severe. Cultivars possessing a high level of resistance to early blight would provide a desirable alternative disease control option. Various levels of resistance to early blight have been reported in tetraploid potatoes (Chattopadhyay and De, 1979; Frank et al., 1979; Le Clerge, 1946), but highly resistant commercial cultivars are not available.

In 1981, resistance to early blight was found in a hybrid diploid population $(2 \mathrm{x}=24)$ of the progenitors of the cultivated potato, Solarium tuberosum L. Group stenotomum (Juz. \& Buk.) Correll and Group phureja (Juz. \& Buk.) Correll (Herriott et al., 1986). This potato material has been classified according to Dodds (1966) following the International Code of Nomenclature for Cultivated Plants. Narrow-sense heritability for early blight resistance in this population was estimated by offspring-midparent regression to be 0.825 (Herriott et al., 1986).

Tetraploid potatoes $(2 \mathrm{x}=48)$ are generally higher-yielding than diploid potatoes; therefore, transfer of genes for early blight resistance from diploid sources to tetraploid clones may be an effective means to increase the level of resistance in commercially acceptable germplasm. One method of accomplishing this transfer is through the use of $2 n$ first-division restitution (FDR) gametes (Hanneman and Peloquin, 1968; Rowe and Sequeira, 1972). Production of these gametes, which are under genetic and environ- mental control (Hermsen, 1984; Veilleux and Lauer, 1981; Veilleux et al., 1982), result from a disruption of normal meiosis. FDR gametes are highly heterozygous (Hermsen, 1984; Mok and Peloquin, 1975a; Mok and Peloquin, 1975b) and transfer nonadditive as well as additive genetic effects from parent to offspring (Mendiburu and Peloquin, 1977; Mok and Peloquin, 1975a; Mok and Peloquin, 1975c).

When these unreduced gametes are combined with $2 \mathrm{n}$ gametes from tetraploids, tetraploid offspring result. Triploid embryos generally abort during development due to breakdown of the endosperm (Hanneman and Peloquin, 1968).

Our objective was to estimate the heritability of early blight resistance in susceptible tetraploid $\times$ resistant diploid hybrids. Heritability cannot be precisely calculated at the tetraploid level, since no one has worked out a way to completely partition out the additive genetic effects. Estimates of heritability calculated in this study are as close as one can come to the true heritability using current estimation techniques for tetraploids.

Our potato source material was obtained from the diploid population screened in 1981 for resistance to early Might disease (Herriott, 1982; Herriott et al., 1986). The proportion of FDR gametes in the reference population was increased in the mid 1970s, when hybrids, made by use of an outside source of germplasm homozygous for production of FDR pollen, were introduced into the population. Plants that were observed to have a high level of disease resistance in 1981 were screened again in 1982. On 3 June 1983, a sample of 83 clones were planted in a field at the Mountain Horticultural Crops Research Station (MHCRS), Fletcher, N.C. They were inoculated with an undetermined concentration of spores of the pathogen in late July and rated for amount of disease and percentage of $2 \mathrm{n}$ pollen in August. The Horsfall-Barratt rating scale for percent defoliation (Horsfall and Barratt, 1945) and a scale $(0=$ no lesions to $5=$ abundant lesions) were used to semiquantitatively estimate the number of lesions per plant. Pollen was collected and evaluated 1 and $13 \mathrm{Aug}$. 1983. It was shaken from the flowers onto a microscope slide, stained with a drop of propiono-carmine, and microscopically examined. The amount of giant pollen present in each sample was estimated using methodology of Quinn et al. (1974).

Seven individuals that were observed to produce from $2 \%$ to $20 \% 2 \mathrm{n}$ pollen were selected for use as pollen parents. On 22 Dec. 1983, eight tubers from each pollen parent were individually planted in $15-\mathrm{cm}$ (1.85 liters) pots in a greenhouse at Raleigh, N.C. Concurrently, 10 tubers from each of four tetraploids ('Atlantic', 'Belchip', 'Saco', and breeding line 71C15-20) were similarly planted for use as female parents in matings during late Feb. and Mar. 1984.

On 14 May, seeds from berries that resulted from 16 different crosses were extracted and air-dried. On 17 May, they were soaked for $24 \mathrm{hr}$ in $1500 \mathrm{ppm}$ gibberellic 
Table 1. Mean early blight apparent infection rates $(r)$ and maturity values for diploid and tetraploid Solanum tuberosum L. parents and their tetraploid offspring.

\begin{tabular}{|c|c|c|c|c|}
\hline Group & Clone & $\mathrm{n}$ & $\begin{array}{l}\text { Mean }^{2} \\
r \text { value }\end{array}$ & $\begin{array}{l}\text { Mean } \\
\text { maturity } \\
\text { value }\end{array}$ \\
\hline Diploid parents & $\begin{array}{r}1 \\
2 \\
38 \\
40 \\
53 \\
61 \\
66 \\
\text { Group } \bar{X}\end{array}$ & $\begin{array}{l}18 \\
16 \\
17 \\
18 \\
13 \\
18 \\
18\end{array}$ & $\begin{array}{l}0.072 \pm 0.019 \\
0.066 \pm 0.031 \\
0.116 \pm 0.102 \\
0.063 \pm 0.022 \\
0.054 \pm 0.022 \\
0.064 \pm 0.025 \\
0.067 \pm 0.019 \\
0.072 \pm 0.034\end{array}$ & $\begin{array}{l}1.65 \\
2.04 \\
1.31 \\
1.94 \\
2.38 \\
2.13 \\
1.83 \\
1.90\end{array}$ \\
\hline $\begin{array}{c}\text { Tetraploid }{ }^{\mathbf{x}} \text { parents } \\
\therefore\end{array}$ & $\begin{array}{c}1 \\
2 \\
6 \\
8 \\
\text { Group } \bar{X}\end{array}$ & $\begin{array}{l}15 \\
18 \\
18 \\
17\end{array}$ & $\begin{array}{l}0.156 \pm 0.090 \\
0.123 \pm 0.025 \\
0.134 \pm 0.034 \\
0.157 \pm 0.051 \\
0.143 \pm 0.050\end{array}$ & $\begin{array}{l}1.11 \\
1.06 \\
1.44 \\
1.06 \\
1.17\end{array}$ \\
\hline Offspring & $\begin{array}{l}1 \times 1 \\
1 \times 53 \\
1 \times 61 \\
1 \times 66 \\
2 \times 66 \\
6 \times 1 \\
6 \times 53 \\
6 \times 61 \\
6 \times 66 \\
8 \times 1 \\
8 \times 2 \\
8 \times 38 \\
8 \times 40 \\
8 \times 53 \\
8 \times 61 \\
8 \times 66 \\
\text { Group } \bar{X}\end{array}$ & $\begin{array}{r}37 \\
60 \\
59 \\
47 \\
46 \\
46 \\
60 \\
60 \\
48 \\
55 \\
57 \\
55 \\
49 \\
57 \\
56 \\
55\end{array}$ & $\begin{array}{l}0.143 \pm 0.095 \\
0.110 \pm 0.091 \\
0.107 \pm 0.050 \\
0.106 \pm 0.070 \\
0.114 \pm 0.055 \\
0.094 \pm 0.068 \\
0.077 \pm 0.053 \\
0.077 \pm 0.029 \\
0.095 \pm 0.055 \\
0.104 \pm 0.080 \\
0.140 \pm 0.094 \\
0.132 \pm 0.087 \\
0.096 \pm 0.030 \\
0.096 \pm 0.057 \\
0.124 \pm 0.080 \\
0.104 \pm 0.031 \\
0.107 \pm 0.064\end{array}$ & $\begin{array}{l}1.09 \\
1.32 \\
1.55 \\
1.48 \\
1.62 \\
1.46 \\
1.57 \\
1.84 \\
1.67 \\
1.45 \\
1.40 \\
1.31 \\
1.61 \\
1.80 \\
1.70 \\
1.65 \\
1.53\end{array}$ \\
\hline
\end{tabular}

${ }^{2}$ The apparent infection rate $r$ was calculated for each plant by regressing the logit of the disease proportion over time. The lower the $r$ value, the higher the level of resistance.

'Tetraploid cultivars: 1 = 'Atlantic'; 2 = 'Belchip'; 6 = 'Saco'; and 8 = breeding line 71C15-20. ${ }^{y}$ A mean maturity value was calculated by averaging values assigned on three different dates. Maturity rating scale: $1=$ senescing with or without flowers; $2=$ many flowers; $3=$ mostly flowers, some buds; $4=$ equal numbers of flowers and buds; $5=$ mostly buds, some flowers; $6=$ small buds; 7 $=$ juvenile, no buds or flowers.

Table 2. Offspring analysis of covariance for percent defoliation of potato plants by early blight with position in field; as covariate, using row means.

\begin{tabular}{lrcr}
\hline \hline Source & df & Mean square & F \\
\hline Block & 3 & 0.0008 & $1.00^{\text {NS }}$ \\
Cross & 15 & 0.0009 & $1.13^{\text {Ns }}$ \\
Position & 1 & 0.0163 & $\vdots$ \\
Error & 44 & 0.0008 & $20.38^{* *}$ \\
Total & 63 & 0.0012 &
\end{tabular}

From offspring-midparent regression: narrow-sense heritability estimate $\left(h^{2}\right)=b=0.815 \pm 0.33=$ $81.5 \% \pm 33 \% ; t=2.508$, Prob. $>t=0.0251^{*}$

acid to break dormancy and then were airdried for $12 \mathrm{hr}$. The seeds were sown in shallow furrows ( $\approx 1 \mathrm{~cm}$ deep) in flats of Fafard mix \#2 (Conrad Fafard Inc., Springfield, Mass.). To prevent damping-off, the seeds were covered with a thin layer of sand and the flats were drenched with an aqueous solution of $324 \mathrm{ppm}(\mathrm{v} / \mathrm{v})$ methyl 1-(butylcarbamoyl)-2-benzimidazolecarbamate (Benlate 50 WP; DuPont de Nemours \& Co., Wilmington, Dela.) plus 194 ppm (v/v) 5-ethoxy3-trichloromethyl-1,2,4-thiadiazole (Truban 30 WP; Mallinckrodt Chemical Works, St. Louis, Me.) Seedlings were transplanted to individual Jiffy-7 pellets (George Ball Co., West Chicago, 111.) in early June.
Seedlings and parental tubers were planted in the field on 3 July 1984. Attempts to create an early blight epidemic that season failed. Tubers from all of the plots were harvested on 16 Oct. and stored for replanting the following season.

On 26 May 1985, before planting, two fields at MHCRS were fumigated by injecting $224 \mathrm{~kg}$ methyl bromide/ha into the soil and covering it with a $1.25-\mathrm{ml}$ plastic tarp. Tubers from the offspring of $4 \mathrm{x}-2 \mathrm{x}$ crosses were planted on 30 May in a randomized complete-block design (RCBD), consisting of four blocks with 16 rows each. There was one cross per row that was represented by 15 plants. Within each row there were three replications of each of five different genotypes. All of the 15 individuals within each row were randomly arranged.

On 31 May, tubers from each parental clones were planted in another field in a RCBD consisting of three blocks, each with three tiers and five rows per tier. Surplus tubers were used to fill in empty rows as needed. There were six plants in each row.

An isolate of $A$. solani was obtained in June from a nearby commercial potato planting. Mycelial transfer from this naturally occurring isolate were increased on lima bean agar. Ten-day-old cultures were induced to sporulate using a modification of techniques described by Barksdale (1968). A hemacytometer was used to determine spore concentrations. A suspension of A. solani $(7 \times$ $10^{2}$ spores $/ \mathrm{ml}$ ) was applied to both fields using a Solo Jet Pak model 425 compressed air sprayer (Solo Inc., Newport News, Vs.) on 1 Aug. On 23 Aug., a suspension with 2.7 $\times 10^{3}$ spores $/ \mathrm{ml}$ was applied such that an average of 32 liters of conidial suspension was applied per hectare.

All of the plants were rated for amount of disease beginning 13 Aug. and thereafter at $\approx 2$-week intervals for a total of four ratings. During the first three rating periods, plants were also assessed for their degree of maturity, based on flowering and degree of senescence. A mean maturity value was calculated for each plant by averaging the three maturity values assigned to each. This value indicates the relative maturity of the plant under consideration, which may range from early to late. Plants were harvested 17 Oct. 1985

Each Horsfall-Barratt rating was converted to a mean percent disease value (Redman, 1969). Since early blight is a disease that increases at a logistic rate (Van der Plank, 1963), the data were transformed using the logit function $\{$ logit $=$ in $[Y /(1-Y)]$, where $\mathrm{Y}=$ disease proportion $\}$. An apparent infection rate ( $\mathrm{r}-$ ) was calculated for each plant by regressing the logit of the disease proportion over time (Van der Plank, 1963). The regression coefficient reflects the level of resistance to early blight a plant possesses.

Resistance is inversely proportional to $r$. Narrow-sense heritability was calculated by regressing offspring $r$ values on midparent $\mathrm{r}$ values. A partial correlation coefficient between $r$ and the mean maturity value was calculated.

There were striking differences in $r$ values between the diploid and tetraploid parents, with most of the diploids having relatively low values (resistant) and the tetraploids having larger values (susceptible) (Table 1). Offspring $r$ values ranged between those of the parents.

Preliminary analyses indicated blocking was not effective. Blocks were arranged across a hill such that each had a portion of higher elevation and a portion of lower elevation, the two being separated by a sprayer drive row. The low portion of each block was more level and less well-drained than the upper portion. Early blight disease progressed much 
more rapidly and to a greater extent in the lower portion than upper portion of each block. The position of the plant within the block (i.e., whether it was in the upper or lower portion), was added to the model as a covariate. Analysis of covariance was done on offspring plot means (i.e., the mean $r$ value for all plants in a row) (Table 2). Least square means (Ray, 1982) were used from the analysis of covariance to adjust for the covariate when estimating heritability. This plot mean model also provided an appropriate denominator for testing blocks and crosses. Neither was significant. The narrow-sense heritability estimate of $0.815 \pm 0.33$ was significant at $P=0.05$.

The estimate of heritability for resistance to early blight disease in transfer from the diploid to the tetraploid level is high. This could be expected, given a heritability estimate of $82.5 \%$ at the diploid level and the fact that FDR gametes in potatoes will transfer $\approx 80 \%$ of the heterozygosity from the diploid (Hermsen, 1984). Because the offspring and parents were grown in relatively similar environments, the assumption underlying parent-offspring regression that there be no environmental correlation between parents and their offspring may not have been met. Heritability would have been biased upwards if such correlation had been present.

Relative maturity is of importance when evaluating potato germplasm for resistance to early blight. Late maturity is not a desirable quality in potato cultivars for the late winter, spring, and early summer production areas. Maturity is of concern since, in some cases, a plant may appear resistant only because the plant is late-maturing.

The partial correlation coefficient between $r$ and the mean maturity value was -0.2086 , which is significant at $P=0.01$. It is not suprising that this value is negative. Early blight is a disease of senescent tissue and, in general, high $r$ values (susceptible plants) may be expected to correlate with low maturity values (senescent tissues), The low correlation coefficient shows that most of the plants in the study are displaying true resistance to disease rather than just apparent resistance due to late maturity.

Futher work with this germplasm might involve backcrossing to the tetraploid parent to increase acceptability in conjunction with several more generations of screening and testing. The size, shape, and color of many of the tubers from the tetraploid offspring resemble commercial cultivars.

Although yield was not regularly recorded, $4.5-\mathrm{kg}$ per plant was common. Based on this information, it is conceivable that a potato cultivar possessing a high level of resistance to early blight disease might be developed.

\section{Literature Cited}

Barksdale, T.H. 1968. A method of screening for resistance to early blight on tomato seedlings. Phytopathology 58:883. (Abstr.)

Chattopadhyay, S.B. and B.K. De. 1979. Studies on resistance of potato varieties against early blight. J. Indian Potato Assn. 6:87-94.

Dodds, K.S. 1966. The evolution of the cultivated potato. Endeavour 25:83-88.

. Frank, J. A., R.E. Webb, and D.R. Douglas. 1979. Evaluation of several USDA potato clones for resistance to early blight. Plant Dis. Rptr. 63:392-394.

Hanneman, R.E. and S.J. Peloquin. 1968. Ploidy levels of progeny from diploid-tetraploid crosses in the potato. Amer. Potato J. 45:255-260.

Harrison, M.D. and J.R. Venette. 1970. Chemical control of potato early blight and its effect on potato yield. Amer. Potato J. 47:81-86.

Hennsen, J.G. 1984. Mechanisms and genetic implications of $2 \mathrm{n}$ gamete formation. Iowa State J. Res. 58:421-434.

Herriott, A.B. 1982. The heritability of resistance to early blight in diploid potatoes (Solanum tuberosum, subsp. phureja and stenofomum). MS Thesis. North Carolina State Univ., Raleigh.

Herriott, A. B., F.L. Haynes, and P.B. Shoe- maker. 1986. The heritability of resistance to early blight in diploid potatoes (Solanum tuberosum, subsp. phureja and stenotomum). Amer. Potato J. 63:229-232.

Horsfall, J.G. and R.W. Barratt. 1945. An improved grading system for measuring plant diseases. Phytopathology 35:655. (Abstr.)

Le Clerge, E.L. 1946. Breeding for resistance to early blight in. the Irish potato. Phytopathology 36:1011-1015.

Mendiburu, A.O. and S.J. Peloquin. 1977. The significance of $2 \mathrm{n}$ gametes in potato breeding. Theor. Applied Genet. 49:53-61.

Mok, D.W.S. and S.J. Peloquin. 1975a. Breeding vahre of $2 n$ pollen (diplandriods) in tetraploid $x$ diploid crosses in potatoes. Theor. Applied Genet. 46:307-314.

Mok, D.W.S. and S.J. Peloquin. 1975b. The inheritance of three mechanisms of diplandroid ( $2 \mathrm{n}$ pollen) formation in diploid potatoes. Heredity 35:295-302.

Mok, D.W.S. and S.J. Peloquin,. 1975c. Three mechanisms of $2 \mathrm{n}$ pollen formation in diploid potatoes. Can. J. Genet. \& Cytol. 17:217-

Quinn, A. A., D.W.S. Mok, and S.J. Peloquin. 1974. Distribution and significance of diplandroids among the diploid Solariums. Amer. Potato J. 51:16-21.

Ray, A.A. (cd.). 1982. SAS user's guide: Statistics, SAS Institute, Inc., Cary, N.C. p. 177178.

Redman, C. E., E.P. King, and I.F. Brown, Jr. 1969. Elanco conversion tables for BarrattHorsfall. Eli Lilly and Co. Research Labs, Greenfield, Ind.

Rowe, P.R. and Luis Sequeira. 1972. Development of potato clones with resistance to bacterial wilt, p. 206-211. In: E.R. French (cd.). Prospects for the potato in the developing world. Symp. Intl. Potato Center, Lima, Peru.

Van der Plank, J.E. 1963. Plant diseases: Epidemics and control. Academic, New York.

Veilleux, R.E. and F.L Lauer. 1981. Variation for $2 \mathrm{n}$ pollen production in clones of Solarium phureja (Juz. and Buk.) Theor. Applied Genet. 59:95-100.

Veilleux, R. E., N.A. McHale, and F.L Lauer. 1982. 2n gametes in diploid Solanum: Frequency and types of spindle abnormalities. Can. J. Genet. Cytol. 24:301-314. 